\section{Exposure of operating room personnel to nitrous oxide during paediatric anaesthesia}

This study was undertaken to quantify the exposure of operating room staff to nitrous oxide during routine paediatric otolaryngeal surgery and to determine the influence of the method of induction of anaesthesia on this exposure. The nitrous oxide exposure of the anaesthetist, the surgeon and the circulating nurse were measured, using body-worn passive atmospheric samplers, during twelve routine paediatric otolaryngeal surgical lists. During six of the lists an inhalational technique, with nitrous oxide, oxygen and halothane, was used for the induction of anaesthesia. During the other six lists anaesthesia was induced using intravenous thiopentone. In all cases, anaesthesia was maintained using nitrous oxide, oxygen and halothane. Regardless of the induction technique used, the mean nitrous oxide exposures of the anaesthetist, the surgeon and the nurse all exceeded the maximum level of $25 \mathrm{ppm} \cdot \mathrm{hr}^{-1}$ recommended by the United States National Institute for Occupational Safety and Health (NIOSH). The use of an intravenous technique for the induction of anaesthesia reduced the nitrous oxide exposure of the anaesthetist and the circulating nurse. This suggests that, although the use of an intravenous induction may reduce exposure to nitrous oxide, the NIOSH recommendations for maximum exposure of operating room personnel to nitrous oxide are currently unattainable in practice.

\section{Key words}

ANAESTHETICS, GASES: nitrous oxide, trace concentrations; TOXICITY: trace concentrations; OPERATING ROOMS: personnel; EQUIPMENT: dosimeters.

From the Department of Anaesthesia, Alberta Children's Hospital at the University of Calgary, Calgary, Alberta.

This paper was presented in part at the Canadian Anaesthetists' Society Annual Meeting in Ottawa, June 1989.

Address correspondence to: Dr. C. Wood, Department of Anaesthesia, Alberta Children's Hospital, 1820 Richmond Road SW., Calgary, Alberta.

Accepted for publication 15th May, 1992.
Ce travail a pour objectif de mesurer le degré d'exposition du personnel des salles d'opération pendant la chirurgie otorhinolaryngologique pédiatrique et l'influence de la méthode d'induction de l'anesthésie sur cette exposition. L'exposition au protoxyde d'azote pour l'anesthésiste, le chirurgien et l'infirmière de service externe est évaluée par l'analyse des échantillons de l'air ambiant pendant le déroulement de douze programmes opératoires otorhino- laryngologiques de pédiatrie. Durant six de ces programmes, une technique inhalatoire comprenant protoxyde d'azote, oxygène et halothane est utilisée pour l'induction. Pendant les six autres, le thiopental intraveineux est utilisé pour l'induire l'anesthésie. Quelque soit la technique utilisée, l'anesthésiste, le chirurgien et l'infirmière sont contact avec des concentra-tions dépassant le niveau maximum de $25 \mathrm{ppm} \cdot \mathrm{hr}^{-1}$ recommandé par le United States National Institute for Occupational Safety and Health (NIOSH). L'utilisation de la technique d'induction intraveineuse a diminué l'exposition au protoxyde d'azote pour l'anesthésiste et l'infirmière. Ceci suggère que, bien que l'utilisation d'une technique d'induction intraveineuse puisse réduire l'exposition au protoxyde d'azote dans les salles d'opération, les recommandation, du NIOSH concernant l'exposition maximale du personnel sont en pratique impossible à atteindre.

Contamination of the operating theatre with trace concentrations of waste anaesthetic gases is an inevitable consequence of the use of inhalational anaesthetic agents. The health risk to operating theatre personnel resulting from chronic exposure to trace concentrations of these agents has been the subject of numerous studies during the last 20 yr. Among the agents studied, the toxic effects of nitrous oxide have been the focus of much attention.

Horace Wells first demonstrated the anaesthetic properties of nitrous oxide in 1844 , but it was not until 1956 that the first adverse side effects from its use were reported. In that year, Lassen described bone marrow surpression in patients sedated with nitrous oxide for long-term ventilation. ${ }^{1}$ Since then, possible adverse effects on bone marrow, psychomotor function, and reproductive function have been described. ${ }^{2-8}$ This has led to concerns regarding possible ill effects from the chronic occupational exposure 
of operating room personnel and dentists to trace levels of nitrous oxide.

Infrared photography has provided graphic pictures of "clouds" of nitrous oxide, in concentrations in excess of $1000 \mathrm{ppm}$, exhaled by an anaesthetised patient, to which nearby personnel are exposed. ${ }^{9}$ Scavenging of anaesthetic gases reduces these concentrations. ${ }^{10,11}$ Even in the presence of scavenging, levels of nitrous oxide have been shown to be higher during anaesthesia for children than for adults. ${ }^{12}$ The potential efficiency of scavenging of waste gases during paediatric anaesthesia is reduced by the regular use of inhalational induction, the assurance of a leak around uncuffed endotracheal tubes, and the use of breathing circuits which require high fresh gas flows.

The recommendations of the National Institute for Occupational Safety and Health (NIOSH) in the United States define a maximum permissable exposure to nitrous oxide of $25 \mathrm{ppm} .{ }^{13}$ A pilot study at the Alberta Children's Hospital substantiated previous observations ${ }^{11,12}$ indicating that a level of $25 \mathrm{ppm}$ is frequently exceeded.

Because of disparities between NIOSH recommendations and measured levels, this evaluation of exposure to nitrous oxide by operating room staff was undertaken. The principal objectives were: (1) to quantify the exposure of operating room personnel to nitrous oxide during an operating day, utilising currently accepted techniques of paediatric anaesthesia and (2) to determine whether the induction technique used affects the total nitrous oxide exposure of those personnel.

\section{Methods}

Approval for the conduct of this study was granted by the Institutional Research Committee. Consent for the participation of staff was not required, but all OR staff were informed of the study. All measurements were made at the Alberta Children's Hospital during 12 routine otolaryngeal surgical lists.

Passive atmospheric samplers (Nitrox Nitrous Oxide Dosimeter, R.S. Landauer, Jr. and Co., 2 Science Rd Glenwood, Illinois) were used to measure the exposure of OR personnel to nitrous oxide. Dosimeters were attatched to the collars of the anaesthetist, the surgeon and the scrub nurse. A fourth dosimeter was placed at the room air exhaust outlet directly behind the anaesthetic machine. The dosimeters were continuously exposed for the whole of the operating day.

The study operating room had a floor area of $36 \mathrm{~m}^{2}$. Room ventilation was provided by a non-recirculating system through four ceiling ducts which delivered a flow rate equivalent to 12 room air changes per hour. Room air was vented via eight equally spaced wall vents located 18 inches from the floor. Direct passive scavenging of the Bain circuit was employed in all cases.
Two anaesthetists participated in the study. Each completed three days during which anaesthesia was induced with nitrous oxide, oxygen and halothane (Group 1) and three days during which induction was with intravenous thiopentone (Group 2). If there was difficulty establishing venous access in Group 2 patients (i.e., cannulation was unsuccessful after two attempts), anaesthesia was induced using oxygen and halothane. Once an adequate airway had been established, using either an endotracheal tube or a mask, anaesthesia was maintained in all patients with $66 \%$ nitrous oxide in oxygen and halothane delivered via a Bain coaxial modification of the Mapleson D circuit. The fresh gas flow was calculated from the patient's weight according to the recommendations of Steward. ${ }^{14}$

The patient's age and weight, the use of a mask or an endotracheal tube, the fresh gas flow rates and the duration of surgery were recorded for every case. Group comparisons were made for each of these factors.

Nitrous oxide exposure was expressed as a time weighted average (TWA) for each exposure. This denotes the average exposure in parts per million of nitrous oxide per hour.

The data were analysed using the SPSS.PC+ statistical package. Demographic data from the patients in the two groups were compared using the unpaired $t$ test. The nature of the surgery and characteristics of the anaesthetic technique were analysed for the groups and the fresh gas flows compared using the Mann Whitney $U$ test. Nitrous oxide exposures recorded at each dosimeter site during each operating day were analysed. Comparisons were made between the two techniques of induction of anaesthesia and between the days on which the two anaesthetists participating in the study were working. All values are expressed as mean \pm standard error of the mean (SEM), and range. Differences are considered significant for $P$ values of less than 0.05 .

\section{Results}

Readings from six of the 48 dosimeters (two surgeons, one nurse and three exhaust outlets) were below the lower limit of detection. These results were inconsistent with the other values obtained and they were excluded from the analysis. In all, 42 dosimeter readings were considered.

There were 66 inductions in Group 1 (nitrous oxide, oxygen, halothane induction of anaesthesia) and 65 inductions in Group 2 (intravenous induction using thiopentone). There were no differences between the two groups with regard to the age or weight of the patients, the incidence of tracheal intubation or the fresh gas flows used. The mean duration of surgery and the mean exposure times of the dosimeters were longer in the inhalational induction group than the intravenous induction group. 
TABLE I Group characteristics for inhalation induction (Group 1) or intravenous induction (Group 2)

\begin{tabular}{lll}
\hline & Group 1( $\left.\mathrm{N}_{2} \mathrm{O}\right)$ & Group 2 (iv) \\
\hline No. cases & 66 & 65 \\
Age $(\mathrm{yr})$ & $4.0(0.35)$ & $4.2(0.35)$ \\
Weight $(\mathrm{kg})$ & $18.0(1.08)$ & $17.2(0.99)$ \\
Fresh gas flow $\left(\mathrm{L} \cdot \mathrm{min}^{-1}\right)$ & $8.4(0.33)$ & $8.3(0.34)$ \\
Duration surgery $(\mathrm{min})$ & $23.7(1.79)$ & $20.7(1.37)$ \\
Exposure time dosimeters (hrs) & $5.6(0.34)$ & $4.6(0.28)$ \\
Number cases intubated & $31(47 \%)$ & $29(45 \%)$ \\
\hline
\end{tabular}

Values expressed as mean (SEM).

TABLE II Surgical procedures done in each of the groups, identified by major procedure

\begin{tabular}{lll}
\hline & Group $J\left(\mathrm{~N}_{2} \mathrm{O}\right)$ & Group 2 (iv) \\
\hline Myringotomy + tubes & 33 & 35 \\
Tonsillectomy & 23 & 27 \\
and/or adenoidectomy & & \\
Tympanoplasty & 2 & 0 \\
Laser endoscopy & 2 & 0 \\
Otoplasty & 1 & 0 \\
Tongue tie & 3 & 1 \\
Excision thyroglossal cyst & 1 & 0 \\
Laryngoscopy & 1 & 1 \\
BSMR & 0 & 1 \\
Total & - & - \\
\hline
\end{tabular}

TABLE III Nitrous oxide exposure $\left(\mathrm{ppm} \cdot \mathrm{hr}^{-1}\right.$ time-weighted average)

\begin{tabular}{llll}
\hline Dosimeter location & Group $1\left(\mathrm{~N}_{2} \mathrm{O}\right)$ & Group 2 (iv) & \\
\hline Anaesthetist & $532(101.1)$ & $219(93.9)$ & $P=<0.05^{*}$ \\
& {$[213-880]$} & {$[55-638]$} & \\
Surgeon & $204(26.0)$ & $188(77.0)$ & $P=\mathrm{NS}$ \\
& {$[124-264]$} & {$[50-477]$} & \\
Nurse & $300(67.0)$ & $72(19.3)$ & $P=<0.01^{*}$ \\
& {$[155-526]$} & {$[23-141]$} & \\
Vent & $87(16.3)$ & $47(12.9)$ & $P=\mathrm{NS}$ \\
All dosimeters & {$[46-141]$} & {$[20-100]$} & \\
& $303(50)$ & $133(33)$ & $P<0.001^{*}$ \\
& {$[46-880]$} & {$[20-638]$} & \\
\hline
\end{tabular}

Values expressed as mean (SEM) [Range].

$* P<0.05$ Mann Whitney $U$ test.

However, as nitrous oxide exposure is quoted in $\mathrm{ppm} \cdot \mathrm{hr}^{-1}$, this should not influence the comparison of the two induction methods (Table I). All patients underwent minor otolaryngeal procedures. The distribution of categories of these procedures was similar in each group (Table II).

Table III shows the nitrous oxide exposures recorded by each dosimeter, expressed as a time weighted average (TWA). The TWA of the anaesthetist was greater than that
TABLE IV Nitrous oxide exposure by anaesthetist $\left(\mathrm{ppm} \cdot \mathrm{hr}^{-1}\right.$ timeweighted average)

\begin{tabular}{llll}
\hline & Anaesthetist I & Anaesthetist 2 & \\
\hline All dosimeters & $262(50.0)$ & $156(34.2)$ & P $=$ NS \\
& {$[37-880]$} & {$[20-526]$} & \\
\hline
\end{tabular}

of the circulating nurse or the surgeon for each method of induction. Mean values at each dosimeter site were higher on the days when an inhalational induction was used than on the intravenous induction days. This difference was significant for the dosimeters worn by the anaesthetist (532 $\mathrm{ppm} \cdot \mathrm{hr}^{-1} \mathrm{cf} 219 \mathrm{ppm} \cdot \mathrm{hr}^{-1} P<0.05$ ), and by the circulating nurse $\left(300 \mathrm{ppm} \cdot \mathrm{hr}^{-1}\right.$, cf $72 \mathrm{ppm} \cdot \mathrm{hr}^{-1} P<$ 0.01 ). For the dosimeters worn by the surgeon (204 $\mathrm{ppm} \cdot \mathrm{hr}^{-1}$ cf $\left.188 \mathrm{ppm} \cdot \mathrm{hr}^{-1} P=\mathrm{NS}\right)$, and sited at the ventilation outlet $\left(87 \mathrm{ppm} \cdot \mathrm{hr}^{-1} \mathrm{cf} 47 \mathrm{ppm} \cdot \mathrm{hr}^{-1} P=\mathrm{NS}\right)$, these differences were not statistically significant.

Table IV shows the total nitrous oxide exposures of the dosimeters recorded on the days when each of the two participating anaesthetists were administering the anaesthetic. Mean exposures were higher during one of the anaesthetist's working days although the difference was not statistically significant (262 ppm $\cdot \mathrm{hr}^{-1}$ cf $156 \mathrm{ppm}$. $\mathrm{hr}^{-1} P=\mathrm{NS}$ ).

\section{Discussion}

The NIOSH recommendation of maximum nitrous oxide levels of $25 \mathrm{ppm} \cdot \mathrm{hr}^{-1}$ was established in 1977 based on a review of the evidence concerning the effects of exposure to trace levels of nitrous oxide. ${ }^{13}$ The measured nitrous oxide exposures of the anaesthetist, the nurse and the surgeon in our study exceeded the NIOSH recommendation regardless of the induction technique used. This implies that despite standard room ventilation and scavenging, the NIOSH recommendation is unattainable using currently accepted methods of paediatric anaesthesia.

A wide range of nitrous oxide exposures was recorded at each dosimeter site and for each method of induction of anaesthesia. The highest mean levels of nitrous oxide exposure for each method of induction were recorded by the dosimeters worn by the anaesthetist (532 and 219 $\mathrm{ppm} \cdot \mathrm{hr}^{-1}$ ). These values are higher than those suggested by earlier studies. Nitrous oxide concentrations in the anaesthetist's breathing zone of $39 \pm 30 \mathrm{ppm}$ have been recorded, during paediatric anaesthesia, with good operating room ventilation and close scavenging. ${ }^{12}$ Nilsson $\mathrm{et} \mathrm{al}$. found that, under similar conditions, a nitrous oxide concentration of $25 \mathrm{ppm}$ was exceeded for $25 \%$ of the anaesthetic time. ${ }^{11}$

Inconsistencies between our results and those of previous studies may be explained by the methods used for the measurement of nitrous oxide levels. Previous work used 
infrared spectrophotometry or gas chromatography to analyse the nitrous oxide concentration in bag samples taken from the breathing zone of the anaesthetist. ${ }^{11,12}$ The Nitrox atmospheric samplers used in our study have been shown to give better correlation than bag sampling with direct infra-red analysis $( \pm 30.5 \% \mathrm{cf} \pm 40 \%) .{ }^{15}$ They are unobtrusive and allowed the usual work pattern to proceed without disruption. This may lead to a more accurate reflection of true nitrous oxide exposures than does the analysis of bag samples.

The use of an intravenous technique for the induction of anaesthesia reduced the nitrous oxide exposures of the anaesthetist and the circulating nurse. The exposure of the surgeon was also reduced by the use of an intravenous induction, but the difference was not statistically significant.

There is evidence for damaging effects of nitrous oxide on the bone marrow and on neurological and psychomotor function. Nitrous oxide oxidizes vitamin B12 and thus decreases DNA production by the inactivation of methionine synthetase. ${ }^{16}$ The effects of this are dosedependent megaloblastic changes seen in the bone marrow which have been demonstrated in patients exposed to $50 \%$ nitrous oxide for periods as short as five hours during cardiac bypass surgery. ${ }^{3}$ Similar bone marrow changes have been reported in dentists who experienced chronic occupational exposure to nitrous oxide in sub-anaesthetic concentrations of $1800 \mathrm{ppm}^{4}$ Long-term exposure to nitrous oxide has also been described as influencing neurological or psychomotor function. A neuropathy characterised by paraesthesia and ataxia has been recognised in habitual abusers of nitrous oxide ${ }^{5,6}$ and in two subjects chronically exposed to nitrous oxide in dental surgeries. ${ }^{7}$ Unfortunately the evidence regarding the effect of trace concentrations of nitrous oxide on psychomotor function is contradictory. One study identified exposure to nitrous oxide in a concentration of $500 \mathrm{ppm}$ as adversely affecting recall of a series of numbers. ${ }^{8}$ Subsequent studies have failed to confirm these results. ${ }^{17,18}$

The extent of adverse effects attributable to chronic occupational exposure to nitrous oxide is not yet fully defined, but it is clear from these studies that it is possible to reduce exposure to waste nitrous oxide and other anaesthetic gases and vapours through alteration of anaesthetic induction technique. Recent improvements in anaesthetic equipment and the development of new drugs may facilitate anaesthetic techniques aimed at reducing operating room concentrations of waste anaesthetic gases. The use of a Brain Laryngeal Mask Airway (Intavent, Colgate Medicals Ltd., Windsor, UK) has been shown to reduce levels of nitrous oxide in the anaesthetist's breathing zone compared with tracheal intubation or a standard facemask. ${ }^{19}$ The use of topical local anaesthetic creams permits painless venepuncture making intravenous induction more acceptable to children. Total intravenous anaesthesia will become a more realistic goal with the introduction into paediatric practice of propofol. It may therefore be possible to reduce the nitrous oxide exposure of operating room staff to levels below those measured in this study.

\section{References}

1 Lassen HCA, Henriksen E, Neukirch F, Kristensen HS. Treatment of tetanus: severe bone-marrow depression following prolonged nitrous oxide inhalation. Lancet 1956; 1: 527-30.

2 Brodsky JB. The toxicity of nitrous oxide. Clinics in Anaesthesiology 1983; 1: 455-67.

3 Amess JAL, Burman JF, Rees GM, Nancekievill DG, Mollin DL. Megaloblastic haemopoiesis in patients receiving nitrous oxide. Lancet 1978; 2: 339-42.

4 Sweeney B, Bingham RM, Amos RJ, Petty AC, Cole JPV. Toxicity of bone marrow in dentists exposed to nitrous oxide. BMJ 1985; 291 : 567-9.

5 Sahenk Z, Mendell JR, Couri D, Nachtman J. Polyneuropathy from inhalation of $\mathrm{N}_{2} \mathrm{O}$ cartridges through a whipped cream dispenser. Neurology 1978; 28: 485-7.

6 Layzer RB, Fishman RA, Schafer JA. Neuropathy following abuse of nitrous oxide. Neurology 1978; 28: 504-6.

7 Layzer RB. Myeloneuropathy after prolonged exposure to nitrous oxide. Lancet 1978; 2: 1227-8.

8 Bruce $D L$, Bach $M J$, Arbit J. Trace anesthetic effects on perceptual, cognitive, and motor skills. Anesthesiology. 1974; 40: 453-8.

9 Allander C, Carlsson P, Hallen B, Ljungqvist B, Norlander $O$. Thermocamera, a macroscopic method for the study of pollution with nitrous oxide in operating theatres. Acta Anaesthesiol Scand 1981; 25: 21-4.

10 Kugel G, Norris LH, Zive MA. Nitrous oxide and occupational exposure: it's time to stop laughing. Anesthesia Progress. 1989; 36: 252-7.

11 Nilsson $K$, Sonander $H$, Stenqvist $O$. Close scavenging of anaesthetic gases during mask anaesthesia. Acta Anaesthesiol Scand 1981; 25: 421-6.

12 Sonander $H$, Stenqvist $O$, Nilsson $K$. Nitrous oxide exposure during routine anaesthetic work. Acta Anaesth Scand 1985; 29: 203-8.

13 Criteria for a recommended standard: occupational exposure to waste anesthetic gases and vapors. National Institute for Occupational Safety and Health, Cincinnati, $\mathrm{OH}$; 1977.

14 Steward DJ. Manual of Pediatric Anesthesia. 2nd ed. New York: Churchill Livingstone Inc., 1985.

15 Bishop EC, Hossain MA. Field comparison between two nitrous oxide $\left(\mathrm{N}_{2} \mathrm{O}\right)$ passive monitors and conventional sampling methods. Am Ind Hyg Assoc J 1984; 45: 812-6. 
16 Koblin DD, Waskell L, Watson JE, Stokstad ELR, Eger EI. Nitrous oxide inactivates methionine synthetase in human liver. Anesth Analg 1982; 61: 75-8.

17 Smith G, Shirley $A W$. Failure to demonstrate effect of trace concentrations of nitrous oxide and halothane on psychomotor performance. $\mathrm{Br}$ J Anaesth 1977; 49: 65-70.

18 Frankhuizen $J L$, Vlek CAJ, Burm AGL, Rejger V. Failure to replicate negative effects of trace anaesthetics on mental performance. Br J Anaesth 1978; 50: 229-34.

19 Sarma VJ, Leman J. Laryngeal mask and anaesthetic waste concentrations (letter). Anaesthesia 1990; 45:

791-2. 